Jurnal Teknologi, 35(E) Dis. 2001: 1-10

(C) Universiti Teknologi Malaysia

\title{
APLIKASI KONSEP DAN KAEDAH LUKISAN KEJURUTERAAN DALAM MATEMATIK OLEH GURU-GURU MATEMATIK DI SEKOLAH MENENGAH TEKNIK SELURUH NEGERI KELANTAN
}

\author{
WIDAD OTHMAN ${ }^{1} \&$ HATTA ISMAIL ${ }^{2}$
}

\begin{abstract}
Abstrak. Penyelidikan ini adalah untuk mengkaji tahap pengetahuan dan aplikasi Lukisan Kejuruteraan dalam mata pelajaran matematik oleh guru-guru matematik di semua Sekolah Menengah Teknik di negeri Kelantan. Semua guru matematik telah digunakan sebagai sampel dalam kajian ini. Set soal selidik yang mengandungi dua bahagian iaitu berbentuk kuantitatif dan kualitatif digunakan bagi mendapatkan keputusan yang lebih menyeluruh. Data dianalisis secara manual dan dikemukakan dalam bentuk peratus. Hasil kajian menunjukkan guru tidak mempunyai pengetahuan tentang integrasi dua mata pelajaran tersebut, tahap apalikasi guru yang mempunyai pengalaman mengajar Lukisan Kejuruteraan adalah baik dan biodata guru seperti pengalaman mengajar dan kelulusan akademik tidak mempengaruhi pengetahuan dan aplikasi guru. Beberapa cadangan dikemukakan untuk memperbaiki kelemahan-kelemahan yang dikenalpasti, antaranya guru-guru perlu diberi pendedahan tentang konsep dan kaedah mengajar Lukisan Kejuruteraan. Di samping itu penyelarasan skema jawapan soalan matematik yang mempunyai kaitan secara langsung dengan Lukisan Kejuruteraan perlu dilakukan.
\end{abstract}

Kata kunci: Aplikasi pengetahuan, konsep, kaedah mengajar, mata pelajaran Lukisan Kejuruteraan dan matematik

\begin{abstract}
The purpose of this research is to identify mathematics teachers level of knowledge in Engineering Drawing, and the application of Engineering Drawing concepts and methodologies in solving related mathematics problems in secondary technical schools in Kelantan. All mathematics teachers were selected as samples. To obtain a more comprehensive result, both quantitative and qualitative data were collected using questionaires. The collected data were analyzed manually and presented in percentages. The results showed that the Mathematics teachers involved in this study have no knowledge integrating both subjects; mathematics and Engineerisng Drawing. However, the application level of teachers who have experience in teaching Engineering Drawing are better and the results showed that academic backkground and years of teaching have no effect on the respondents knowledge and application level. To improve the current situation, it is suggested that Mathematics teachers be exposed to the concepts and methodologies of Engineering Drawing. In addition an answer scheme for Mathematics questions which have applications in Engineering Drawing subject need to be coordinated.
\end{abstract}

Keywords: Application of knowledge, concepts, teaching methods, engineerisng drawing subject and mathematics,

\footnotetext{
$\overline{1 \& 2}$ Fakulti Pendidikan, Universiti Teknologi Malaysia.
} 


\subsection{PENGENALAN}

Dalam abad ke-18, bermulalah era Lukisan Kejuruteraan (LK) moden. Gespard Monge telah memperkenalkan lukisan ortografik yang digunakan sehingga kini. Namum begitu LK moden dianggap bermula pada abad yang ke-19 apabila beberapa peralatan lukisan mula digunakan seperti papan lukisan, sesiku-T, sesiku set dan alatan lukisan geometri yang lain (Mohammad Khairuddin, 1989).

Jika ditinjau dari orang pertama memperkenalkan LK, didapati hampir semua yang terlibat dengan LK mempunyai asas yang kukuh dalam matematik. Contohnya kaedah pelan dan dongakan mula-mula diperkenalkan oleh seorang ahli matematik Perancis Gespard Monge (1746-1818). Monge membayangkan suatu pepejal terletak di dalam sebuah kotak kaca dan unjuran ortografik pepejal dilukis pada mukamuka kotak itu (Bell, 1951). Pendekatan Monge ini adalah berlandaskan kepada konsep unjuran yang dicipta oleh tokoh Itali yang bernama Leonardo Da Vinci (Kementerian Pendidikan Malaysia, 1991). Beliau menggunakan konsep ini untuk menyampaikan idea dan pelbagai rekaan baru. Sementara Eulid membincangkan Geometri berasaskan pemerhatian terhadap bentuk-bentuk yang tersirat dalam alam (Syed Abdul Kader, 1995). Beliau menambah, bidang geometri merupakan salah satu bidang utama matematik yang diajar dalam sistem persekolahan Malaysia selain bidang Aljabar dan Kalkulus.

Jika dibandingkan sukatan pelajaran matematik Sijil Pelajaran Malaysia (SPM), dengan Lukisan Geometri dan Kejuruteraan bagi Sijil Pelajaran Malaysia Vokasional (SPMV) dan SPM, terdapat beberapa topik yang mempunyai persamaan secara langsung dalam konsep dan kaedah penyelesaiannya (Kementerian Pendidikan Malaysia, 1988) seperti berikut:

\section{MATEMATIK}

Pelan dan Dongakan

Penjelmaan

Garis dan Satah Tiga Matra

Lokus, Panjang, Luas dan Isipadu, Trigonometri dan Bulatan

Pecahan, Nisbah, Purata, Skala dan Keserupaan.

\section{LUKISAN KEJURUTERAAN}

Ortografik dan Pandangan Tambahan

Pembesaran dan Pengecilan, Skala

Isometri dan Ortografik

Geometri Satah

Skala dan Membahagi Garisan

Matlamat kurikulum Baru Sekolah Menengah (KBSM) bagi mata pelajaran matematik adalah untuk memperkembangkan pemikiran mantik, analitis, bersistem dan kritis, kemahiran penyelesaian masalah serta kebolehan menggunakan ilmu pengetahuan matematik supaya seseorang individu dapat berfungsi dalam kehidupan seharian dengan berkesan. Selaras dengan kenyataan di atas maka guru matematik 
perlulah menggunakan konsep dan kaedah LK dalam pengajaran matematik yang berkaitan, kerana wujudnya perkaitan secara langsung antara kedua-dua mata pelajaran tersebut. Misalnya dalam pembinaan ortografik yang menggunakan unjuran titik. Menurut Klausmeier (1974), konsep merupakan pembinaan mental individu untuk mencapai kecemerlangan pada peringkat yang lebih tinggi. Berdasarkan pernyataan Klausmeier, konsep dilihat sebagai pengalaman dan mempunyai hubungan yang sangat penting antara input luaran dan perlakuan yang nyata. Adalah sesuatu yang jelas bahawa pengajaran secara bersepadu begitu penting dan perlu bagi penanggapan konsep dengan baik (Abu Bakar, 1991). Oleh itu pengajaran dan pembelajaran matematik dan LK mestilah secara bersepadu dari segi konsep dan kaedah terutama di Sekolah Menengah Teknik yang mempunyai kemudahan mencukupi. Contohnya, penyelesaian masalah bagi topik pelan dan dongakan dalam mata pelajaran matematik akan lebih berkesan jika guru terus menerapkan konsep unjuran sudut seperti mana yang diamalkan dalam LK.

\subsection{PERNYATAAN MASALAH}

Kajian ini adalah untuk mengenalpasti tahap pengetahuan dan aplikasi konsep dan kaedah mengajar LK dalam mata pelajaran oleh guru-guru matematik di Sekolah Menengah Teknik di Negeri Kelantan.

\subsection{PERSOALAN KAJIAN}

(i) Adakah pengalaman mengajar dan kelulusan akademik guru mempengaruhi tahap pengetahuan dan aplikasi guru dalam penyelesaian masalah matematik yang berkaitan dengan LK.

(ii) Apakah pandangan guru tentang kaitan antara konsep matematik dengan LK.

(iii) Apakah pandangan guru tentang aplikasi konsep LK dalam penyelesaian masalah matematik yang berkaitan.

(iv) Adakah guru mempunyai pengetahuan tentang tajuk-tajuk yang mempunyai kaitan secara langsung antara matematik dengan LK.

(v) Adakah guru dapat mengaplikasikan konsep dan kaedah LK dalam penyelesaian masalah matematik yang berkaitan.

(vi) Adakah guru yang mempunyai pengalaman mengajar LK dapat mengaplikasikan konsep dan kaedah mengajar LK dengan baik dalam penyelesaian masalah matematik yang berkaitan.

\subsection{METODOLOGI KAJIAN}

Kajian ini melibatkan kedua-dua bentuk iaitu kualitatif untuk mendapatkan keputusan yang lebih tepat dan menyeluruh. Bentuk kualitatif digunakan untuk mendapatkan keputusan tahap aplikasi guru secara lebih tepat apabila menjawab soalan yang diberikan. 
Bentuk kuantitatif yang lebih objektif akan menghasilkan keputusan yang tepat dari segi pandangan dan pengetahuan guru terhadap konsep LK. Kajian dijalankan di semua Sekolah Menengah Teknik di Negeri Kelantan iaitu di SM Teknik Pengkalan Chepa, SM Teknik Tanah Merah dan SM Teknik Kuala Krai. Seluruh populasi yang terdiri daripada 15 orang guru matematik digunakan sebagai sampel kajian.

Instrumen yang digunakan bagi mengumpul data terdiri daripada satu set soal selidik. Setiap set soal selidik mengandungi dua bahagian iaitu bahagian A dan B.

Bahagian A mengandungi lima item mengenai biodata yang memerlukan responden menanda kenyataan yang paling sesuai sahaja. Bahagian B pula dibahagikan kepada dua bahagian iaitu $\mathrm{B}(\mathrm{I})$ dan $\mathrm{B}(\mathrm{II})$. Dalam bahagian $\mathrm{B}(\mathrm{I})$, terdapat 11 item yang berkisar tentang aplikasi konsep dan kaedah serta keperluannya, pengetahuan serta kefahaman konsep.

Bahagian B(II), terdiri daripada dua soalan ujian kualitatif yang perlu dijawab oleh guru. Jawapan yang diperlukan hanyalah dalam bentuk lakaran sahaja. Dua soalan tersebut ialah pelan dan dongakan dan pembesaran mengikut nisbah sisi.

\subsection{KEPUTUSAN DAN PERBINCANGAN}

Merujuk kepada Jadual 1, terdapat seorang sahaja daripada 15 orang guru yang memiliki ijazah Sarjana. Guru berkenaan mendapat markah 50\% sahaja dan hanya mengaplikasikan konsep binaan unjuran. Beliau mengajar di tingkatan 4 dan 5 dan mempunyai pengalaman mengajar antara 5 hingga 10 tahun.

Terdapat $86.7 \%$ guru matematik yang memiliki Ijazah Sarjana Muda. Hanya 10 orang daripada mereka yang menjawab soalan dan mendapat markah antara 60\% hingga 70\%. Dua daripada tiga orang guru Sarjana Muda yang tidak menjawab langsung mengajar di tingkatan 4; manakala seorang lagi mengajar di tingkatan 4 dan 5. Kesemua mereka mempunyai pengalaman mengajar kurang daripada 5 tahun.

Seorang guru tunggal yang memiliki diploma telah mendapat markah $70 \%$ di samping mengaplikasikan konsep binaan unjuran dan membuat tandaan titik sepenuhnya. Guru berkenaan mengajar di tingkatan 4 dan mempunyai pengalaman mengajar kurang daripada 5 tahun.

Perkara menarik hasil daripada analisis ini (merujuk pada Jadual 1) ialah tentang tiada wujudnya kaitan antara biodata guru dari segi tempoh mengajar, tingkatan mengajar dan kelulusan akademik tertinggi dengan aplikasi konsep dan pengetahuan guru tentang perkaitan antara mata pelajaran matematik dengan LK. Kelulusan Sarjana, Ijazah dan Diploma tidak mempengaruhi tahap aplikasi konsep guru dalam menyelesaikan masalah matematik yang berkaitan.

Guru pemegang Diploma yang mempunyai pengalaman mengajar kurang dari lima tahun contohnya mencapai markah 70\%, berbanding guru pemegang Sarjana yang mempunyai pengalaman mengajar melebihi 5 tahun tetapi hanya mencapai markah $50 \%$. 
Jadual 1 Bahagian B(II): Jawapan Responden Berkenaan dengan Pelan Dongakan dan Pandangan Tambahan

\begin{tabular}{|c|c|c|c|c|c|c|c|c|c|c|c|}
\hline \multirow[t]{2}{*}{ No. } & \multicolumn{3}{|c|}{$\begin{array}{c}\text { Jumlah } \\
\text { Pandangan } \\
\text { yang dibina }\end{array}$} & \multicolumn{3}{|c|}{ Biodata Guru } & \multicolumn{5}{|c|}{ Aplikasi Konsep } \\
\hline & 1 & 2 & 3 & $\begin{array}{c}\text { Penga- } \\
\text { laman } \\
\text { (Tahun) }\end{array}$ & $\begin{array}{c}\text { Ting- } \\
\text { katan } \\
\text { Menga- } \\
\text { jar }\end{array}$ & $\begin{array}{c}\text { Kelulusan } \\
\text { Akademik } \\
\text { Tertinggi }\end{array}$ & $\begin{array}{c}\text { Sudut } \\
\text { Unjuran } \\
\text { (Pertama/ } \\
\text { Ketiga }\end{array}$ & $\begin{array}{l}\text { Binaan } \\
\text { Unjuran }\end{array}$ & $\begin{array}{l}\text { Garisan } \\
\text { Rujukan }\end{array}$ & $\begin{array}{c}\text { Tandaan } \\
\text { Titik } \\
\text { (21 } \\
\text { tandaan) }\end{array}$ & $\begin{array}{c}\text { Markah } \\
(\%)\end{array}$ \\
\hline 1. & & & $\mathbf{X}$ & $5-10$ & $4 \& 5$ & SARJANA & - & $\mathbf{X}$ & - & - & 50 \\
\hline 2. & & & $\mathbf{X}$ & $<5$ & $4 \& 5$ & IJAZAH & - & $\mathbf{X}$ & - & 9 & 70 \\
\hline 3. & & & $\mathbf{X}$ & $<5$ & $4 \& 5$ & IJAZAH & - & $\mathbf{X}$ & - & 21 & 70 \\
\hline 4. & & & $\mathbf{X}$ & $5-10$ & $4 \$ 5$ & IJAZAH & - & $\mathbf{X}$ & - & 21 & 70 \\
\hline 5. & & & $\mathbf{X}$ & $<5$ & $4 \& 5$ & IJAZAH & - & $\mathbf{X}$ & - & - & 60 \\
\hline 6. & & & $\mathbf{X}$ & $5-10$ & $4 \& 5$ & IJAZAH & - & $\mathbf{x}$ & - & - & 60 \\
\hline 7. & & & $\mathbf{X}$ & $5-10$ & $4 \& 5$ & IJAZAH & - & $\mathbf{X}$ & - & - & 60 \\
\hline 8. & & & $\mathbf{X}$ & $11-15$ & $4 \& 5$ & IJAZAH & - & $\mathbf{X}$ & - & - & 60 \\
\hline 9. & & & $\mathbf{X}$ & $5-10$ & 5 & IJAZAH & - & - & - & 21 & 50 \\
\hline 10. & $\mathbf{x}$ & & & $5-10$ & 4 & IJAZAH & - & - & - & - & 10 \\
\hline 11. & $\mathbf{X}$ & & & $5-10$ & $4 \& 5$ & IJAZAH & - & - & - & - & 10 \\
\hline 12. & & & & $<5$ & 4 & IJAZAH & - & - & - & - & $\mathrm{T} / \mathrm{J}$ \\
\hline 13. & & & & $<5$ & 4 & IJAZAH & - & - & - & - & $\mathrm{T} / \mathrm{J}$ \\
\hline 14. & & & $\mathbf{X}$ & $<5$ & $4 \& 5$ & IJAZAH & - & - & - & - & $\mathrm{T} / \mathrm{J}$ \\
\hline 15. & & & $\mathbf{X}$ & $<5$ & 4 & DIPLOMA & - & $\mathbf{X}$ & - & 21 & 70 \\
\hline
\end{tabular}

Nota: i. $\mathbf{X}$ adalah tandaan bagi jawapan/binaan yang diterima

ii. $\mathbf{T} / \mathbf{J}$ dan ( - ) merujuk pada tidak jawab.

iii. Tandaan Titik ialah membuat setiap tandaan pada pandangan dalam lukisan sebagai rujukan.

Jadual 2 menunjukkan 86.7\% guru mengatakan konsep matematik dan konsep LK mempunyai kaitan. Tiada seorangpun responden mengatakan konsep matematik dan LK tidak mempunyai kaitan. Kesemua guru juga mengatakan konsep matematik merentas kurikulum. Kesedaran menganai perkaitan yang wujud ini haruslah difahami dengan jelas oleh semua guru. Perkaitan ini tidak harus dilihat wujud pada satu hala sahaja. Seandainya guru melihat hanya konsep matematik yang perlu diaplikasikan ke dalam LK dan bukan sebaliknya, maka guru telah salah faham. Sebenarnya LK adalah sebahagian daripada bidang matematik (Syed Abdul Kader, 1995). 
Jadual 2 Taburan Responden Mengikut Konsep Matematik dan Perkaitannya dengan LK.

\begin{tabular}{|l|l|c|c|}
\hline \multirow{2}{*}{ Perkara } & \multirow{2}{*}{ Jawapan } & \multicolumn{2}{|c|}{$\begin{array}{c}\text { Guru } \\
\text { Matematik }\end{array}$} \\
\cline { 2 - 4 } & & Jum. & $\%$ \\
\hline \multirow{2}{*}{$\begin{array}{l}\text { Konsep Asas Matematik Merentasi } \\
\text { Kurikulum. }\end{array}$} & YA & 15 & 100 \\
\cline { 2 - 4 } & T/PASTI & 0 & 0 \\
\cline { 2 - 4 } & TIDAK & 0 & 0 \\
\hline & & & \\
\hline \multirow{2}{*}{$\begin{array}{l}\text { Konsep Matematik dan konsep } \\
\text { L/Kej. Mempunyai Kaitan. }\end{array}$} & YA & 2 & 13 \\
\cline { 2 - 4 } & T/PASTI & 0 & 0 \\
\cline { 2 - 4 } & TIDAK & & 13.3 \\
\hline
\end{tabular}

Jadual 3 memaparkan hasil kajian yang menjawab persoalan kajian 3. Keputusan yang diperolehi tidak begitu memuaskan di mana hanya $60 \%$ guru yang mengakui konsep LK boleh diaplikasikan dalam penyelesaian masalah matematik yang berkaitan dengan LK, manakala 33.3\% lagi tidak pasti tentang perkara tersebut. Hasil ini menunjukkan dengan jelas bahawa terdapat guru yang tidak memahami mahupun mengetahui bahawa LK adalah sebahagiann daripada bidang matematik. Mereka menganggap bahawa matematik dan LK adalah mata pelajaran yang berasingan dan memerlukan bentuk pengajaran dan pembelajaran secara terpisah. Mereka tidak dapat melihat aplikasi teknik, konsep dan kaedah LK dalam Matematik. Jika dilihat pada organisasi kandungan dan struktur LK, aspek pertama yang diberi penekanan ialah geometri satah yang mencakupi prinsip-prinsip matematik (Pusat Perkembangan Kurikulum, 1990). Maka wajarlah jika dikatakan bahawa setiap masalah matematik yang berkaitan dengan LK boleh diselesaikan dengan menggunakan teknik, konsep serta kaedah LK dengan berkesan.

Integrasi antara mata pelajaran Matematik dengan LK seharusnya berlaku terutama di sekolah-sekolah aliran teknikal, kerana mata pelajaran LK dan Matematik berada di bawah naungan satu bumbung.

Jadual 3 Taburan Responden Mengikut Aplikasi Konsep Matematik dan LK

\begin{tabular}{|l|l|c|c|}
\hline \multirow{2}{*}{ Perkara } & \multirow{2}{*}{ Jawapan } & \multicolumn{2}{|c|}{$\begin{array}{c}\text { Guru } \\
\text { Matematik }\end{array}$} \\
\cline { 3 - 4 } & & Jum. & $\%$ \\
\hline Konsep LK boleh diaplikasikan & YA & 9 & 60.0 \\
\hline Sepenuhnya dalam penyelesaian & T/PASTI & 5 & 33.3 \\
\hline Masalah matematik berkaitan & TIDAK & 1 & 6.7 \\
\hline
\end{tabular}


Dapat diandaikan bahawa pendedahan tentang perkaitan antara matematik dengan LK boleh berlaku dengan mudah dan berkesan. Walau bagaimanapun, hasil kajian menunjukkan keadaan sebaliknya; iaitu mata pelajaran Matematik dan LK dipisahkan. Sepatutnya kerjasama antara guru LK dengan guru Matematik dalam mencari suatu kaedah pengajaran yang lebih berkesan perlu diwujudkan. Hubungan yang baik dari segi bertukar-tukar pendapat dan ilmu pengetahuan antara guruguru matematik dengan LK akan mewujudkan suasana pencambahan ilmu secara lebih dinamik dan berkesan. Cara begini bukan sahaja akan meningkatkan pembelajaran pelajar terutama dalam penyelesaian masalah matematik dan LK yang berkaitan. Jika guru-guru berkenaan berada dalam keadaan yang berasingan, maka sudah tentu kedua-dua mata pelajaran tersebut akan menjadi lebih terasing dan seolah-olah tiada kaitan antara keduanya.

Jadual 4 menggambarkan kefahaman guru tentang perkaitan antara tajuk-tajuk matematik dengan LK. Dalam soal selidik Bahagian A, guru perlu memadankan topik matematik dengan LK yang mempunyai kaitan secara langsung. Hanya 29.3\%

Jadual 4 Taburan Responden Mengikut Padanan Tajuk-Tajuk Matematik dengan LK yang Berkaitan

\begin{tabular}{|c|c|c|}
\hline \multirow{2}{*}{$\begin{array}{c}\text { Bil. } \\
\text { Responden }\end{array}$} & \multicolumn{2}{|c|}{ Guru Matematik } \\
\hline & Betul & Salah \\
\hline 1. * & 2 & 3 \\
\hline 2. & 2 & 3 \\
\hline 3. * & 3 & 2 \\
\hline 4. & 1 & 4 \\
\hline 5. & 1 & 4 \\
\hline 6. & 1 & 4 \\
\hline 7. & 1 & 4 \\
\hline 8. & 1 & 4 \\
\hline 9. & 1 & 4 \\
\hline 10. & 1 & 4 \\
\hline $11 .^{*}$ & 4 & 1 \\
\hline 12. & 0 & 5 \\
\hline 13. & 4 & 1 \\
\hline 14. & 0 & 4 \\
\hline 15. & 0 & 4 \\
\hline Peratus Keseluruhan: & $29.3 \%$ & $70.7 \%$ \\
\hline Peratus Guru yang Berpengalaman Mengajar LK: & $60 \%$ & $\mathbf{4 0} \%$ \\
\hline
\end{tabular}

Nota: * merujuk kepada guru matematik yang pernah mengajar LK. 
sahaja guru yang dapat menjawab dengan betul, manakala 70.7\% gagal menunjukkan padanan dengan tepat. Namun demikian $60 \%$ guru yang mempunyai pengalaman mengajar LK dapat memberikan padanan dengan tepat berbanding $40 \%$ yang gagal berbuat demikian. Walau bagaimanapun, pengetahuan guru mengenai perkaitan atau pertindanan tajuk-tajuk Matematik dengan LK masih rendah. Akibatnya, jika guru tidak mempunyai pengetahuan yang baik tentang tajuk-tajuk yang berkaitan, bagaimanakah guru dapat mengaplikasikan konsep LK dalam pengajaran mereka. Guru seharusnya sedar tentang kepentingan pembelajaran dan pengajaran secara bersepadu demi meningkatkan keprofesionalisme diri mereka, seterusnya boleh melahirkan pelajar yang lebih matang dan kreatif. Guru perlu mempunyai pengetahuan yang mendalam bagi bidang yang diajarnya (Atan Long, 1986).

Merujuk kepada Jadual 5, didapati tiada seorang pun guru yang dapat mencapai markah melebihi 70\%. Daripada jumlah keseluruhan, 66.7\% guru mendapat markah antara 50\% hingga 70\%, manakala 13.3\% mendapat markah 10\% dan selebihnya tidak menjawab soalan.

Dari segi aplikasi konsep dan kaedah yang diperlukan, tiada seorang pun guru yang menyatakan atau menetapkan sudut unjuran yang digunakan. Daripada jumlah 15 orang guru tersebut, $60 \%$ telah membuat garisan binaan pada setiap lukisan mereka. Namun pada bahagian sudut unjuran, tiada seorang pun guru yang membuat garisan rujukan semasa membina pandangan tambahan.

Dapatan seterusnya dapat menyokong dan memperkukuhkan lagi apa yang telah dibincangkan sebelum ini. Guru-guru didapati tidak dapat mengaplikasikan konsep LK apabila menyelesaikan masalah matematik yang berkaitan (Jadual 5). Paling mengecewakan ialah terdapat tiga orang guru yang tidak menjawab langsung dan dua orang guru yang hanya mendapat 10\%. Dapatan ini jelas menunjukkan bahawa guru sebenarnya tahu tentang perkaitan antara dua mata pelajaran tersebut, tetapi mereka tidak mampu untuk mengaplikasikannya apabila menyelesaikan masalah berkaitan, apatah lagi untuk mengaplikasikannya dalam pengajaran. Jika perkara sebegini berterusan, maka pembelajaran akan menjadi tidak bermakna (Ausubel, 1968) dan pengajaran akan menjadi statik.

Jadual 5 juga memaparkan jawapan yang diberikan oleh tiga orang guru matematik yang mempunyai pengalaman mengajar LK. Dua orang guru tersebut mendapat $70 \%$ manakala seorang lagi mendapat $60 \%$. Ketiga-tiga orang guru tersebut membuat binaan unjuran dengan tepat. Guru-guru yang mempunyai pengalaman mengajar LK telah menunjukkan kemampuan untuk mengaplikasikan konsep dan kaedah LK dengan baik dalam penyelesaian masalah Matematik yang berkaitan. Mereka telah memberikan jawapan yang begitu ringkas dan padat kerana menggunakan kaedah LK dan tidak bergantung pada pengiraan semata-mata. Seandainya guruguru tersebut dapat mengaplikasikannya dalam pengajaran, maka proses pembelajaran akan lebih bermakna. Daya kreativiti pelajar akan dapat diperkaya dan diperkembangkan. Kesepaduan atau integrasi antara subjek dapat diwujudkan. 
Jadual 5 Jawapan Soalan Berkaitan dengan Pelan Dongakan dan Pandangan Tambahan (Jawapan Hanyalah dalam Bentuk Lakaran Sahaja)

\begin{tabular}{|c|c|c|c|c|c|c|c|c|c|c|c|}
\hline \multirow[t]{2}{*}{ No. } & \multicolumn{3}{|c|}{$\begin{array}{c}\text { Jumlah } \\
\text { Pandangan }\end{array}$} & \multicolumn{4}{|c|}{ Jawapan (\%) } & \multicolumn{4}{|c|}{ Aplikasi Konsep } \\
\hline & 1 & 2 & 3 & $\begin{array}{c}\text { Tepat } \\
(80-100)\end{array}$ & $\begin{array}{c}\text { Kurang } \\
\text { Tepat } \\
(50-70)\end{array}$ & $\begin{array}{c}\text { Tidak } \\
\text { Di } \\
\text { terima/ } \\
\text { Tidak } \\
\text { Jawab }\end{array}$ & $\begin{array}{c}\text { Jumlah } \\
(\%)\end{array}$ & $\begin{array}{l}\text { Sudut } \\
\text { Unjuran }\end{array}$ & $\begin{array}{l}\text { Binaan } \\
\text { Unjuran }\end{array}$ & $\begin{array}{c}\text { Garisan } \\
\text { Rujukan }\end{array}$ & $\begin{array}{c}\text { Tandaan } \\
\text { Titik }\end{array}$ \\
\hline 1. (GP) & & & $\mathrm{X}$ & & $\mathrm{X}$ & & 70 & - & $\mathrm{X}$ & - & 9 \\
\hline 2. & $\mathrm{X}$ & & & & & $\mathrm{X}$ & 10 & - & - & - & - \\
\hline 3. (GP) & & & $\mathrm{X}$ & & $\mathrm{X}$ & & 70 & - & $\mathrm{X}$ & - & 21 \\
\hline 4. & - & - & - & & - & $\mathrm{TJ}$ & - & - & - & - & - \\
\hline 5. & & & $\mathrm{X}$ & & $\mathrm{X}$ & & 50 & - & - & - & 21 \\
\hline 6. & & & $\mathrm{X}$ & & $\mathrm{X}$ & & 60 & - & $\mathrm{X}$ & - & 21 \\
\hline 7. & - & - & - & - & - & $\mathrm{TJ}$ & - & - & - & - & - \\
\hline 8. & $\mathrm{X}$ & & & & & $\mathrm{X}$ & 10 & - & - & - & - \\
\hline 9. & & & $\mathrm{X}$ & & $\mathrm{X}$ & & 50 & - & $\mathrm{X}$ & - & - \\
\hline 10. (GP) & & & $\mathrm{X}$ & & $\mathrm{X}$ & & 60 & - & $\mathrm{X}$ & - & - \\
\hline 11. & & & $\mathrm{X}$ & & $\mathrm{X}$ & & 60 & - & $X$ & - & - \\
\hline 12. & & & $X$ & & $X$ & & 70 & - & $X$ & - & 21 \\
\hline 13. & & & $\mathrm{X}$ & & $\mathrm{X}$ & & 60 & - & $X$ & - & - \\
\hline 14. & - & - & - & - & - & $\mathrm{TJ}$ & - & - & - & - & - \\
\hline 15. & & & $X$ & & $X$ & & 60 & - & $\mathrm{X}$ & - & - \\
\hline
\end{tabular}

Nota: i. $\mathrm{X}$ adalah tandaan bagi jawapan/binaan yang diterima

ii. $\mathrm{T} / \mathrm{J}$ dan (-) merujuk pada titik jawab.

iii. No. (GP) adalah merujuk kepada guru matematik yang mempunyai pengalaman mangajar LK.

\section{0 RUMUSAN DAN CADANGAN}

Hasil kajian menunjukkan bahawa guru-guru matematik mempunyai pengetahuan tentang perkaitan antara Matematik dengan LK. Walau bagaimanapun, mereka tidak mempunyai kefahaman yang baik tentang tajuk-tajuk Matematik-LK yang berkaitan. Kelulusan akademik dan pengalaman mengajar tidak mempengaruhi kebolehan guru Matematik untuk mengaplikasikan konsep LK dalam penyelesaian masalah Matematik. Tetapi pengalaman mengajar dalam LK menjadi asas kukuh kepada keberkesanan aplikasi konsep, teknik dan kaedah LK dalam Matematik.

Pengalaman mengajar LK telah mewujudkan kefahaman dan pengetahuan mengenai LK yang nyata menjadi asas penting dalam integrasi kedua-dua subjek 
tersebut. Maka adalah wajar jika guru-guru Matematik diberikan pendedahan dalam matapelajaran LK secara formal agar pengaplikasian konsep LK dalam pengajaran Matematik dapat berlaku secara lebih berkesan dan bermakna. Apabila perkaitan antara Matematik dengan LK telah dimanfaatkan, maka pembelajaran akan menjadi lebih bermakna, dinamik dan kreatif.

\section{RUJUKAN}

Abu Bakar Nordin. 1987. Memahami Psikologi Pembelajaran. Kuala Lumpur: Kementerian Pendidikan Malaysia. Abu Bakar Nordin. 1991. Kurikulum-Perspektif dan Pelaksanaan. Kuala Lumpur: Pustaka Antara.

Abu Hassan Kassim ( ? ). Kaedah Penyelidikan dalam Pendidikan. Skudai: Uiversiti Teknologi Malaysia.

Atan Long. 1986. Pedagogi: Kaedah Am Mengajar. Petaling Jaya: Fajar Bakti Sdn. Bhd.

Ausubel, D. P. 1968. Educational Psychology: A Cognitive View. New York: Holt, Rinehart \& Winston.

Aziz Nordin. 1992. Matematik Sebagai Asas Untuk Mengikuti Kursus Kejuruteraan. Prosiding Simposium Kebangsaan Sains Matematik Ke-V. 56-59, Skudai: Universiti Teknologi Malaysia.

Bell E. T. 1986. Technical Drawing. Eighth Edition, New York: Macmillan Publishing Company.

Kementerian Pendidikan Malaysia. 1988. Sukatan Pelajaran Sekolah Menengah-Matematik. Pusat Perkembangan Kurikulum: Kementerian Pendidikan Malaysia.

Kementerian Pendidikan Malaysia. 1990. Sukatan Pelajaran KBSM Lukisan Kejuruteraan. Pusat Perkembangan Kurikulum: Kementerian Pendidikan Malaysia.

Kementerian Pendidikan Malaysia. 1991. Lukisan Kejuruteraan Tingkatan 4 KBSM. Kuala Lumpur: Dewan Bahasa dan Pustaka.

Klausmeier, H.j., Ghatala, E. S. dan Dorothy A. F. 1974. Conceptual Learning and Development: A Cognitive View. New York: Academic Press.

Ling Chu Poh. 1989. Literasi Pemikiran dalam Kurikulum Baru Sekolah Menengah di Malaysia: Perspektif dan Tumpuan yang Diingini. Suara Pendidik: Keluaran Khas. Persatuan Pendidik Malaysia.

Mohammad Khairuddin Yahya. 1989. KBSM Matematik Tingkatan 2. Kuala Lumpur: Berita Publishing Group.

Mohd. Najib Ghafar. 1977. Asas Penyelidikan Sains Sosial. Skudai: Universiti Teknologi Malaysia.

Ng Chik Leong. 1992. KBSM Matematik Tingkatan 5. Shah Alam: Pustaka Budaya Ilmu.

Noor Azlan Ahmad Zanzali. 1995. Penyelidikan Kualitatif dalam Pendidikan. Jurnal Pendidikan Universiti Teknologi Malaysia. Jilid 1, Bil. 2; 12-33.

Nurul 'Ain Abdul Rahman. 1995. Kemampuan Pelajar Pusat Pendidikan Persediaan di ITM Menggunakan Konsep dan Kemahiran Matematik untuk Menyelesaikan Masalah Bermatematik dalam Mata Pelajaran Fizik. Tesis Sarjana, UTM: Skudai.

Persidangan Kebangsaan Pendidikan Teknikal dan Kejuruteraan. 1995. Pendekatan Baru Terhadap Pendidikan Teknikal dan Kejuruteraan. Skudai: Universiti Teknologi Malaysia.

Philip J. D. dan Reuben H. 1981. The Mathematical Experience. Boston: Birkhhausa.

Pusat Perkembangan Kurikulum. 1990. Sukatan Pelajaran Kurikulum Bersepadu Sekolah Menengah Tingkatan IV-V. Lukisan Kejuruteraan. Kuala Lumpur: Kementerian Pendidikan Malaysia.

Ralph W. Tyler. Terjemahan oleh Haji Kamaruddin Hussin dan Hazil Abdul Hamid. 1991. Prinsip Asas Kurikulum dan Pengajaran. Skudai: Universiti Teknologi Malaysia.

Sharifah Alwiah Alsagoff (1983). Ilmu Pendidikan Pedagogi. Kuala Lumpur: Heinemann Asia.

Syed Abdul Kader Aljunid. 1995. Peranan dan Kepentingan Matematik dalam Pendidikan Kejuruteraan-Isu, Masalah dan Cabaran. Persidangan Kebangsaan Teknikal dan Kejuruteraan. Skudai: Universiti Teknologi Malaysia.

Romberg T. A. 1976. Individual Guided Mathematics. Wesley Publishing Company: Addison.

Wan Zahid Mohd Noordin. 1993. Wawasan Pendidikan: Agenda Pengisian. Kuala Lumpur: Nurin Enterprise.

Wong Sin Mong. 1990. KBSM Matematik Tingkatan 3. Kuala Lumpur. DAB Enterprise Sdn. Bhd. 